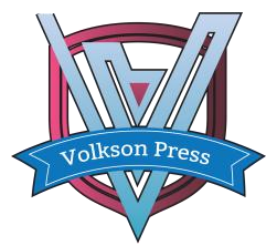

Contents List available at VOLKSON PRESS

Mechanical and Control Engineering (MCE)

DOI : http://doi.org/10.26480/wsmce.01.2017.164.166

\title{
RESEARCH AND APPLICATION OF INTEGRAL SEPARATION PID CONTROL BASED ON FUZZY CONTROL IN INTELLIGENT CAR
}

\author{
Xiaolan Xie ${ }^{1,2}$, Xiaohua Tao ${ }^{*}$, Jili Chen ${ }^{1,2}$ \\ ${ }^{1}$ College of Information Science and Engineering, Guilin University of Technology, Guilin, Guangxi Zhuang Autonomous Region, China. \\ ${ }^{2}$ Guangxi Universities Key Laboratory of Embedded Technology and Intelligent Information Processing (Guilin University of Technology), China. \\ *Corresponding Author Email:1156036381@qq.com
}

This is an open access article distributed under the Creative Commons Attribution License, which permits unrestricted use, distribution, and reproduction in any medium, provided the original work is properly cited

\section{ARTICLE DETAILS}

\section{Article History:}

Received 02 october 2017 Accepted 06 october 2017

Available online 11 november 2017

Keywords

Integral Separation PID control algorithm, fuzzy control, Intelligent Car

\section{ABSTRACT}

The wheel-type robot has a high degree of nonlinearity in the process of intelligent tracking control in a closedloop environment. The speed and direction of the wheel-type robot need real-time control both in the straight path and the curved path. Therefore, the system uses the Integral Separation PID control algorithm to control the speed and fuzzy control to adjust the car's front direction. The integral PID control algorithm used in this paper not only guarantees the control accuracy of the system, but also avoids system shock caused by excessive overshoot as a result of external factors. At the same time, the system also has a faster response speed.

\section{INTRODUCTION}

With the upsurge of IoT (Internet of thing ) and artificial intelligence, embedded devices attract people's attention, especially in the industrial field, the military field, the service industry, and intelligent robots. Collection and processing of information as well as control system and control program of intelligent vehicle is very similar with smart cars [1-4]. The smart car's control system as a platform to better Development the future application of smart cars. The control of intelligent car is divided into two parts: path detection and direction control.

The smart car in this paper uses the STC12C5A60S2 of single-chip microcomputer of Hong Jing Technology Co., Ltd.,as a microprocessor to collect the information of the pavement by Photosensitive sensor Formed by LED and light sensor, and then convert the collected information into the data that the machine can recognize by using AD converter, Integrate the separated PID algorithm to deal with the converted data to determine the specific location of the car, according to the relative position of the car and the black line to issue commands to control the motor speed and steering, in order to control the car's actual movement [5]. The overall structure of the car shown in Figure 1.

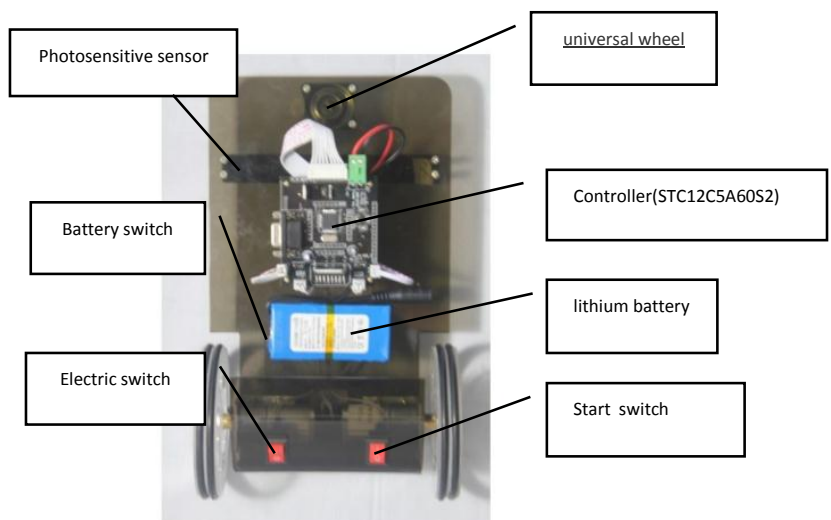

Figure 1: The overall structure of the smart car

\section{SIGNAL ACQUISITION AND PROCESSING}

\subsection{Photosensitive sensor}

Intelligent car control system uses a STC12C5A60S2 microcontroller of Hong Jing Technology Co. Ltd..The information collection is composed of seven light-

sensitive sensors [6]. The principle is that the degree of reflection of light and the resistance is different according to the detection surface of different colors. Therefore, we can use it to detect different color depth. Within the effective detection range, the LED emits white light, irradiates the detection surface, and the detection surface reflects part of the light. The photo resistance detects the intensity of this light and converts it into a signal that can be recognized by the robot.

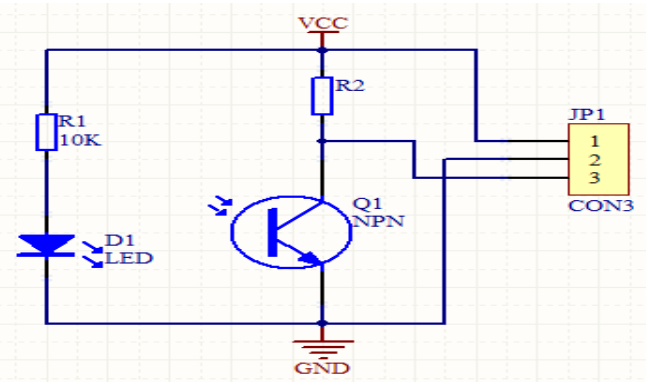

Figure 2: Photosensitive resistance sensor circuit structure

2.3 Data collection

For different photoresistors, the returned value of white line and black line exits a slight gap, and the difference in light intensity also affects the data collected [7]. and in order for the smart car to better determine the location, before each start, we have to move the light sensor back and forth 7-10 times around the path, and in order to collect data in a specific environment, and the maximum resistance of each sensor range into memory for post-processing.

3. Analysis and calculation 
During the ride, the smart car will constantly collect road information. The data collected at different locations will vary. The closer you get to the black line, the weaker the returned light is and the larger the resistance is, the larger the returned value is. On the contrary, the smaller the value. Then, depending on the size of the data returned, determine the location of the car.

Calculated as follows:

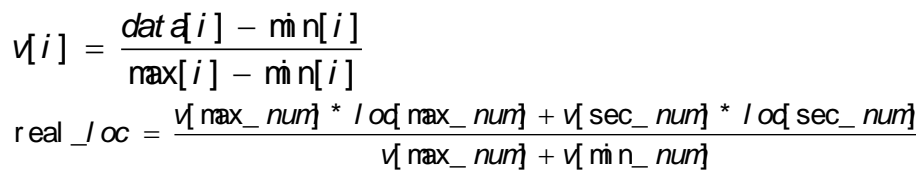

Explanation:

dat $a$ : A set of data collected by a smart car in real time during driving;

$\mathrm{m} n$ : the minimum set of seven group of photosensitive sensors; $\operatorname{nax}$ : the maximum set of seven group of photosensitive sensors;

$V$ : The set of the proportion. that is, the set of the ratio of the light intensity of the sensors feel and the maximum resistance range of the sensor;

næx_num: the index of the largest data in v set;

sec_num : the index of the second largest data in v set;

real $I O C$ : the relative distance of the car during driving. In fact, the width of black line on speedway is $2 \mathrm{~cm}$ and reduce the game time,

we just choose the data that returned by two sensors with the highest proportion (in fact, the higher the proportion, the more pressure lines) and used them to estimate the relative position of the car.

\section{INTEGRAL SEPARATION PID CONTROL ALGORITHM}

\subsection{Basic PID control algorithm}

The basic PID control algorithm is based on the classical control theory. According to the deviation between the input value and the given value, the controlled object is controlled by using a linear combination of deviation ( $K_{P}$ ), integral $\left(K_{l}\right)$, and derivative $\left(K_{D}\right)$ as a controlled variable, called the PID algorithm. PID algorithm block diagram shown in Figure 3.

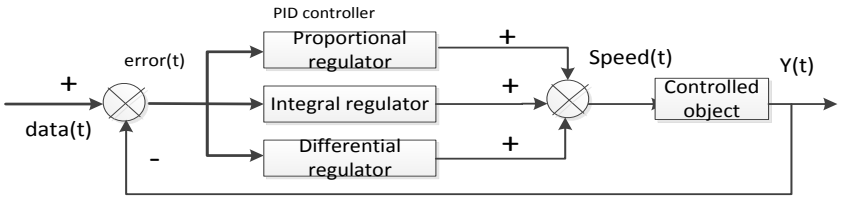

Figure 3: Block diagram of PID control algorithm

In the computer control system, the use of digital PID controller, the control law:

$$
\begin{aligned}
& \operatorname{error}(k)=\text { dat } a(k)-Y(k) \\
& u(k+1)=K_{p}{ }^{*} \operatorname{error}(k)+K_{l}{ }^{*} \sum_{i=0}^{k} \operatorname{error}(i)+K_{d}{ }^{*}[\operatorname{error}(k)-\operatorname{error}(k-1)]
\end{aligned}
$$

dat $a k)$ : the value given for the kth time; $Y(k)$ : the output value for the kth time; $U(k)$ : the kth output control amount; $\operatorname{error}(k+1)$ : The k+1th deviation ; $\operatorname{error}(k-1)$ : the k-1th deviation; $K_{p}$ : Scale factor; $K_{l}$ : integral coefficient; $K_{D}$ : differential coefficient.

\subsection{Integral separation PID control algorithm}

The traditional PID algorithm integrates the integral factor in order to eliminate the static error and improve the control accuracy. However, in actual operation, when the smart car increases or decreases greatly, such as starting, ending and turning, in a short time, the system output deviation will be larger and result in the accumulation of deviation integrals during the operation of the car, resulting in control over the control system allows the maximum range of control corresponding to the limit control, and even causing large vibration of the system, finally resulting in uncontrollable conditions [8].

The basic idea of integral separation PID algorithm is that when the controlled amount exceeds a given control range, the integral factor is canceled to improve the stability of the system and the adjustment range increases. When the controlled amount is still within the control range, using integral factor to eliminate static error and improve control accuracy.

Integral separation of the PID algorithm model is as follows:

$$
U k+1)=k_{p} \operatorname{error}(k)+\beta k_{l} \sum_{j=0}^{k} \operatorname{error}(j) T+\frac{k_{d}(\operatorname{error}(k)-\operatorname{error}(k-1))}{T}
$$

Where, $T$ is the sampling time, the system is set to 90 clock cycles, $\beta$ is the switching coefficient of the Integral item.

$$
\beta=\left\{\begin{array}{l|l}
1 & |\operatorname{error}(k)| \leq \varepsilon, \\
0 & |\operatorname{error}(k)| \succ \varepsilon
\end{array}\right.
$$

situation. If $\mathcal{E}$ is too large, you cannot achieve the purpose of separation of integral. If $\mathcal{E}$ is too small, you cannot enter the integration area.

\section{FUZZY CONTROL}

Due to the diversity of the road and the complexity of the pavement and the difference of the light intensity, the whole control system of the smart car is a nonlinear control [9]. We cannot fit a certain mathematical model to control the operation of the car, so we use real-time control. Real-time control rules are shown as figure 4:

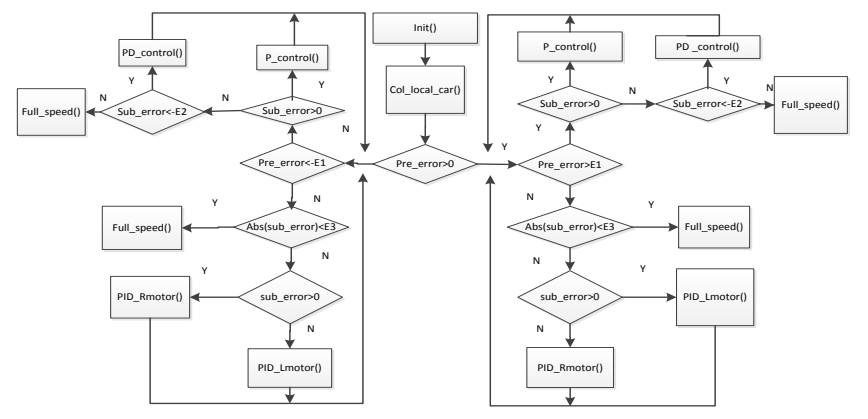

Figure 4: Block diagram of Integral separation PID algorithm control motor Explanation: After initializing the PWM and ADC, the car starts to scan the ground information to calculate the relative displacement of the car. When the error occurs, it is judged whether the pre _error exceeds the threshold $E 1$. If it exceeds $E 1$, the $P$ and $P D$ factors are used for emergency control [10]. Because the $P$ factor is adjusted to a greater extent than the $P D$ factor, $P$ control factor is used when error value continue to increase and $P D$ control factor is used when the error has a tendency to shrink. If the pre_error does not exceed $E 1$, the car currently can still travel normally and keep the speed unchanged and fine tune through the PID algorithm to control the direction of the front. If the sub_error is within the range of $E 3$, it implied that the car can be considered in a safe area and can move forward at full speed without any adjustment.

\section{CONCLUSION}

By the research of the STC12C5260S2 microcontroller, photosensitive sensors, motor speed and steering and integral separation of the PID algorithm to explore and research the intelligent car control system , realizing the application of intelligent car control system under fuzzy control by integral separation of the PID algorithm. The experiment proves that the scheme is not only feasible, but also has good stability and high control precision.

\section{ACKNOWLEDGMENTS}

This research work was supported by the National Natural Science Foundation of China (Grant No.61762031), Guang Xi Key Research and Development Plan, GuangXi key Laboratory of Embedded Technology and Intelligent Information Processing.

\section{REFERENCES}

[1] Zhang, H., He, Z.Q., Yang, R.W., Zhou, J.K., Wei, Z.M. 2017. Intelligent Vehicle Tracking Control Based on Cortex-M4 and Its Implementation [M]. 
Guizhou University, 04, 023.

[2] Tan, C., Wang, L.Y., Zhao, H.M., Su, C. 2015. Design of a multiple function intelligent car based on modular control [C]. China three Gorges University.

[3] Wan, X.F., Xing, Y.S., Cai, L.X. 2009. Fuzzy control system for intelligent car [C]. Nanchang University.

[4] Li, B. 2016. Design of smart car software system based on closed-loop control algorithm and PID optimization algorithm [J]. China agricultural University.

[5] Ye. J. 2016. Control algorithm research on smart car based on fuzzy pid [J], Anhui university of science and technology.
[6] Jin, L., Li, W., Li, B. 2010. Study on steering characteristics of a six wheeled smart car[J], Wuhan University of Technology.

[7] Ding, R. 2016. Design of Wheeled Robot Motion Control [J], Guangzhou Institute of Engineering Technology.

[8] Chenglong, L.V., Li, J., Guo, F., Sun, X., Yu, J., Zhang, J. 2017. Design of Double Closed Loop Fuzzy PID DC Speed Control System of Intelligent Car [J], Nanhua University.

[9] Zhang, H., Ma, T., Xie, R., Liu, S. 2013. Expert PID control algorithm in the application of tracing robot [J]. North University of china.

[10] Dong, Z., Li, M., Xiao, Y. 2016. Design and implementation of automatic intelligent tracking car based on ccd [C]. Dalian Nationality University. 